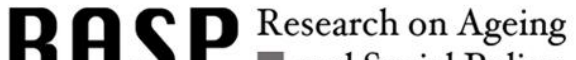
and Social Policy

Instructions for authors, subscriptions and further details:

http://rasp.hipatiapress.com

\title{
The University of the Third Age and Active Ageing: European and Asian-Pacific Perspectives.
}

Marta Font Palomar

1) Universitat Rovira i Virgili. Spain

Date of publication: January $30^{\text {th }}, 2020$

Edition period: January 2020- June 2020

To cite this article: Font Palomar, M. (2020). The University of the Third Age and Active Ageing: European and Asian-Pacific Perspectives. [Review of the book]. Research on Ageing and Social Policy, 8(1), 115-117. doi: 10.4471/rasp.2020.4938

To link this article: http://dx.doi.org/10.4471/rasp.2020.4322

\section{PLEASE SCROLL DOWN FOR ARTICLE}

The terms and conditions of use are related to the Open Journal System and to Creative Commons Attribution License (CCAL). 


\section{Review}

Formosa, M. (Ed.). (2019). The university of the third age and active ageing: European and Asian-Pacific perspectives (Vol. 23). Springer.

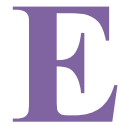

1 libro "The University of the Third Age and Active Ageing. European and Asian-Pacific Perspectives" es una recopilación de testimonios de diferentes universidades para la tercera edad, editado por Marvin Formosa. En este libro los autores y autoras buscan analizar el movimiento creciente de universidades para personas de la tercera edad, profundizando en los orígenes, la evolución y los impactos que han tenido estas Universidades para la Tercera Edad (U3A) en diferentes países de Europa, Asia y el Pacífico.

Desde el inicio del libro Formosa hace referencia a la relación entre el aprendizaje a lo largo de la vida y el envejecimiento activo, como dos caras de una misma moneda imposibles de disociar. En la introducción se presentan los ejemplos de U3A, como iniciativas de éxito que unen estas dos caras de la moneda: el lifelong learning y el active ageing. Además, se describe como estos tienen un impacto, no sólo en la promoción de la educación entre personas mayores, sino también como foco de transformación de las comunidades.

A lo largo de los 18 capítulos del libro divididos en dos bloques, los autores y autoras analizan las experiencias de U3A en distintos países y profundizan en los beneficios e implicaciones desde los diferentes contextos. Con esta recopilación de experiencias, los autores y autoras buscan promover el diálogo y el intercambio de conocimiento, al mismo tiempo que aportar sobre las experiencias más próximas.

En el bloque sobre las perspectivas europeas, se lleva a cabo un repaso por las experiencias de universidades para la tercera edad en el Reino Unido, Islandia, Italia, Alemania, Malta, Polonia, Rusia, España y Suecia. A lo largo de este recorrido se puede observar cómo emergen diferencias entre los distintos modelos, ofreciendo diferentes modelos organizativos en función del contexto en el que se encuentran. Sin embargo, en todos los países, las 
U3A contribuyen significativamente a un envejecimiento activo, con impacto no solo a nivel educativo, sino en la salud física y mental, la inclusión social y las relaciones con la comunidad y la autonomía de las personas.

Por otro lado, el bloque dedicado a las perspectivas de Asia y del Pacífico analiza cómo se iniciaron y cómo se han desarrollado las experiencias de U3A en los distintos países. A través del análisis de las experiencias de Australia, China, Hong Kong, Líbano, Malasia, Nueva Zelanda, Corea del Sur, Taiwán y Tailandia, los autores y autoras analizan el papel de las U3A en dar respuesta a los retos de los diferentes países, a nivel de cohesión cultural y social, mejora de las condiciones de vida y de salud de los colectivos más desfavorecidos y empoderamiento y promoción de la autonomía de las personas mayores.

A grandes rasgos, se dividen las experiencias de universidades U3A de todo el mundo entre las que siguen un modelo francófono, más tradicional y basado en clases magistrales en los campus universitarios y un modelo británico, más basado en la ayuda mutua y la flexibilización, no sólo del currículum sino también de los espacios y las metodologías. No obstante, aunque las experiencias mostradas sean diversas a nivel de gestión, organización y programas educativos, todas ponen el foco en los beneficios del lifelong learning, haciendo énfasis en las potencialidades de las personas mayores y en el valor social que añaden a las universidades. A lo largo de los capítulos del libro se evidencian los esfuerzos internacionales para promover un envejecimiento activo (active ageing) a través de la promoción de oportunidades educativas. Además, se refleja también cómo potenciar estas experiencias educativas en gente mayor, no sólo comporta beneficios para estas personas, sino que representa acabar con la discriminación que tradicionalmente han sufrido en el ámbito de la educación superior y convertir la universidad en el foco de la transformación de la comunidad.

Finalmente, en las conclusiones, Formosa analiza las similitudes y diferencias entre los dos contextos analizados y también algunas barreras y futuros retos que todavía tiene que afrontar el movimiento de las U3A, como la polarización entre el modelo francófono y británico o las desigualdades existentes en términos de género, etnia y clase social.

Marta Font Palomar, Universitat Rovira i Virgili marta.font@urv.cat 